УДК 655.344.022.7-181.4

( С. Ф. Гавенко, д-р техн. наук, проф., В. В. Бернацек, канд. техн. наук, доц., М. Т. Лабецька, канд. техн. наук, асист., УАД, Львів, Україна

\title{
ДОСЛІДЖЕННЯ ВПЛИВУ \\ ТЕХНОЛОГІЧНИХ РЕЖИМІВ ДРУКУВАННЯ НА ЯКІСТЬ ОФСЕТНИХ ВІДБИТКІВ
}

\begin{abstract}
В роботі проведено експериментальні дослідження впливу зміни технологічних режимів друкування різними фарбами на якість тоновідтворення відбитків шляхом встановлення їх репродукційно-графічних показників. В результаті проведеного аналізу побудованих графічних залежностей зміни градаційної передачі фарб досліджуваних взірців і кольоропроби встановлено оптимальну швидкість друкування паковань офсетним способом.
\end{abstract}

Ключові слова: офсетний друк; паковання; відбиток; кольоропроба; тоновідтворення; градаційна передача; оптична густина; якість.

\section{Постановка проблеми}

Сучасне паковання, окрім своїх основних функцій захищати виріб всередині і робити його придатним для транспортування, повинне виконувати й додаткові функції: бути розумно спроектованим, функціонально розробленим та належним чином надрукованим, оскільки відіграє все більш важливу роль у рішеннях потенційних клієнтів про купівлю. Тому не варто недооцінювати маркетинговий аспект, який включає в себе сучасне паковання. Ключовою моделлю для оцінки його якості $€$ тип використовуваного процесу друку. Найпоширенішою технікою задруковування пакувальної продукції є офсет завдяки своїй універсальності, економічності та функціональності.
Хоча на сьогоднішній день частка продукції, віддрукованої офсетним способом, у світі поступово витісняється технологією цифрового друку, цей спосіб відтворення інформації найкраще підходить для отримання реалістичних, чітких і якісних зображень, щоб задовольнити зростаючий попит на декоративне паковання, тому офсетний друк залишається домінуючою технологією на поліграфічному ринку. Це підкріплюється постійними технологічними інноваціями та вдосконаленнями існуючого обладнання. Так, сучасні покоління офсетних машин більш продуктивні та конструктивно складніші, з іншого боку, нові технології, що впроваджуються в офсетних друкарських машинах, приносять більш просте 
управління та більш швидку зміну пластин, що значно скорочує час та підвищує економічність виконання замовлень навіть невеликого обсягу, що є особливо важливим, враховуючи сучасні тенденції усіх сегментів поліграфічного ринку щодо зниження тиражів та персоналізації друку. Високоавтоматизовані офсетні друкарські машини, окрім високої швидкості та меншої собівартості продукції, дозволяють зменшити кількість відходів до шести разів, що суттєво впливає на рентабельність усього виробництва. Інтелектуальні програмні рішення, які вже проникли у всі сегменти виробничого процесу від інтерфейсу замовлення друку, контролю над усіма процесами друкування та оздоблення до автоматизованих складів та доставки товару замовнику, дозволяють здійснювати постійний контроль над усіма життєво важливими функціями машини, що значно скорочує час простоїв, викликаних збоями, та сприяе більш економічним інтервалам обслуговування [1-6].

Як відомо, застосування усіх нововведень вимагає посилення контролю на всіх стадіях виробничого процесу, тому проведення експериментальних досліджень впливу зміни технологічних режимів друкування на якість відтворюваної інформації $€$ необхідним та актуальним завданням.

\section{Мета роботи}

Дані дослідження проводились з метою встановлення впливу технологічних режимів офсетного способу друку, а саме зміни його швидкості, на якість отри- маних кольорових відбитків. Шляхом побудови графічних залежностей зміни градаційної передачі фарб досліджуваних взірців і кольоропроби та проведення їх аналізу оцінити якість та точність відтворення кольорового зображення, віддрукованого офсетним способом друку при заданих умовах, а саме максимальну відповідність до оригіналу.

\section{Об'єкти і методи дослідження}

Серед популярних матеріалів, представлених на українському поліграфічному ринку, для проведення досліджень були обрані картон «Арктика» масою 1 м² 215 г, який широко використовується для виготовлення паковань, та два комплекти фарб фірми Huber cepiï Resista та Reflecta. Фарби Huber Group cepiï Resista мають високий ступінь захисту до стирання, виготовлені згідно технології без мінеральних масел та підходять для будь-яких друкарських машин з традиційним або спиртовим зволоженням. Тріадні фарби Reflecta особливо підходять для високоглянцевих робіт на крейдованому папері, а також на всмоктуючих і некрейдованих задруковуваних паперах. Ця серія поліграфічних фарб відрізняється високим контрастом, мінімальним розтискуванням і утворенням стабільної емульсії. Завдяки хорошій стійкості до стирання і середній швидкості висихання допускається універсальне застосування цієї серії.

Цифрова кольоропроба оригінал-макету паковання із зобра- 
женням широкого спектру і великої гамми кольорів була віддрукована на цифровій машині Xerox 700i Digital Color Press; друк аналогової кольоропроби проведено на офсетній машині Heidelberg GTO 52 [7, 8] з використанням комплекту термальних пластини (СMYK) фірми Ipagsa Industrial S.L. (Іспанія) при трьох швидкостях друку: 3000, 5000 і 7000 арк./год (в подальшому взірець № 1, № 2 і № 3 відповідно) та лініатурі растру 175 Ipi. Засобом для оцінювання якості відбитків були створені нами згідно з міжнародним стандартом ISO 12647 тестові шкали з полями півтонів і тонів, а також ряд шкал для контролю якості офсетного способу друку Ugra/ Fogra Digital Print Scale Control $[9,10]$. Вимірювання оптичної густини віддрукованих взірців проводили на спектроколориметрі Gretag SPM 50. Для проведення статистичної обробки отриманих результатів експериментальних досліджень використовувався пакет програмного забезпечення Microsoft Office Excel 2010.

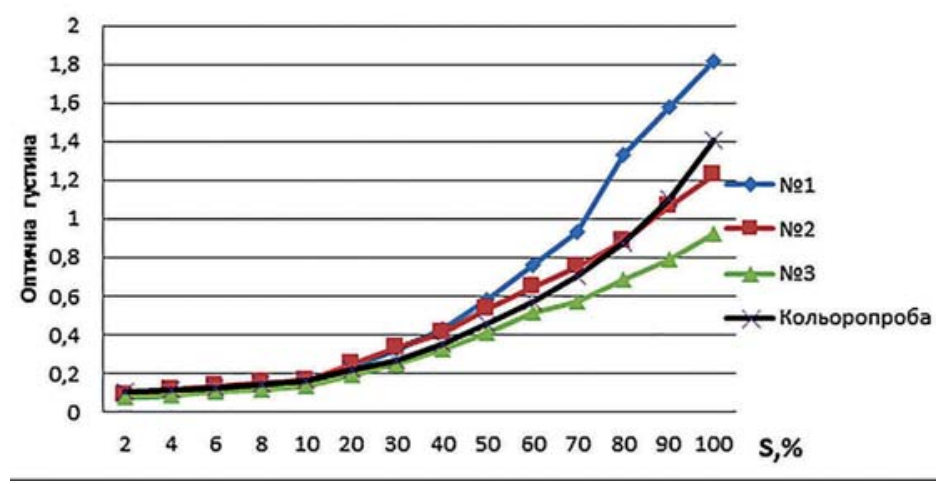

a

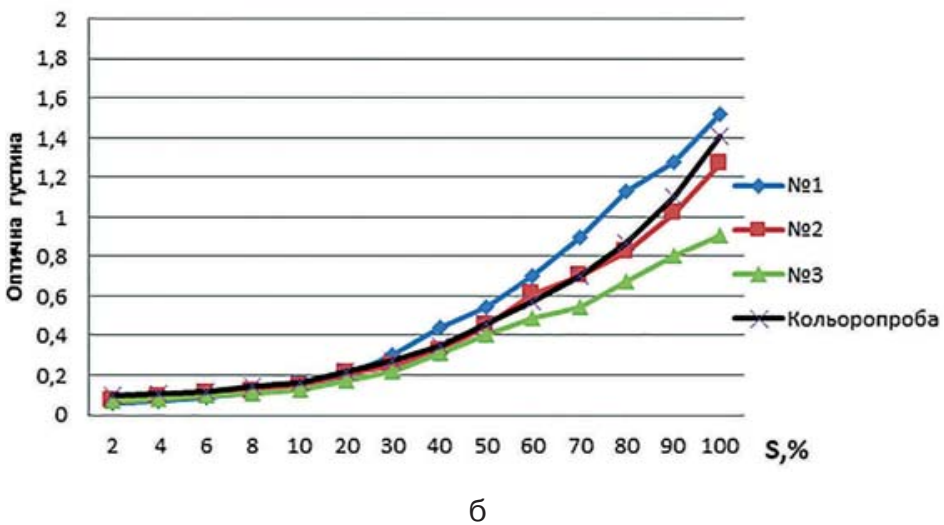

Рис. 1. Градаційна передача голубої фарби Суan Huber Group cepiï: a - Resista, б - Reflecta при швидкостях друку № 1, № 2, № 3 


\section{Результати проведених досліджень}

Для проведення оцінювання якості та точності відтворення кольорового зображення, віддрукованого офсетним способом друку при змінній швидкості, побудовано графічні залежності зміни градаційної передачі фарб досліджуваних взірців і кольоропроби (рис. 1-4).

Аналіз градаційної передачі голубої фарби всіх досліджуваних взірців (рис. 1) свідчить, що показники оптичної густини в світ- лих ділянках більш-менш відповідають кольоропробі; в півтонах у взірця № 1 починають зростати і така тенденція продовжується в темних ділянках; знижуються для взірця № 3, починаючи з півтонів до темних ділянок. Найбільш наближеною до кольоропроби виявилась оптична густина у взірця № 2 для двох комплектів фарб Resista та Reflecta.

На рис. 2 спостерігається незначне зростання оптичної густини у взірця № 2 для пурпурної фарби, починаючи з поля 10 \%,

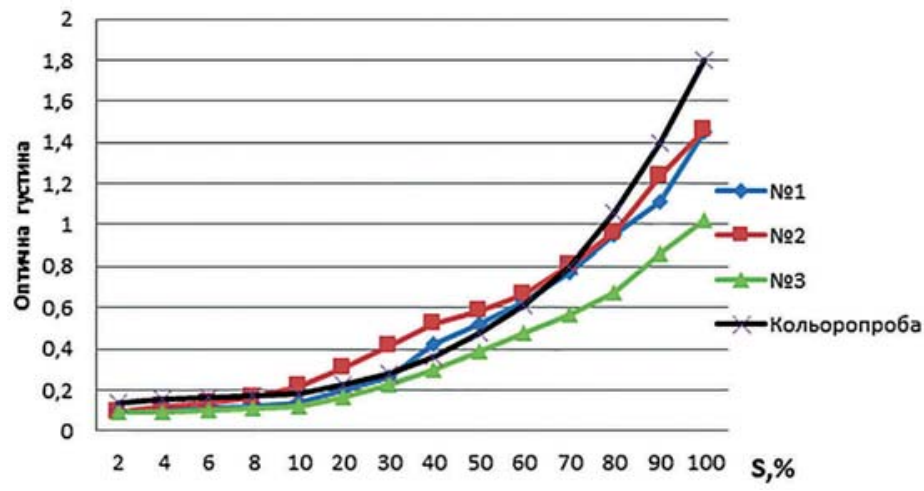

a

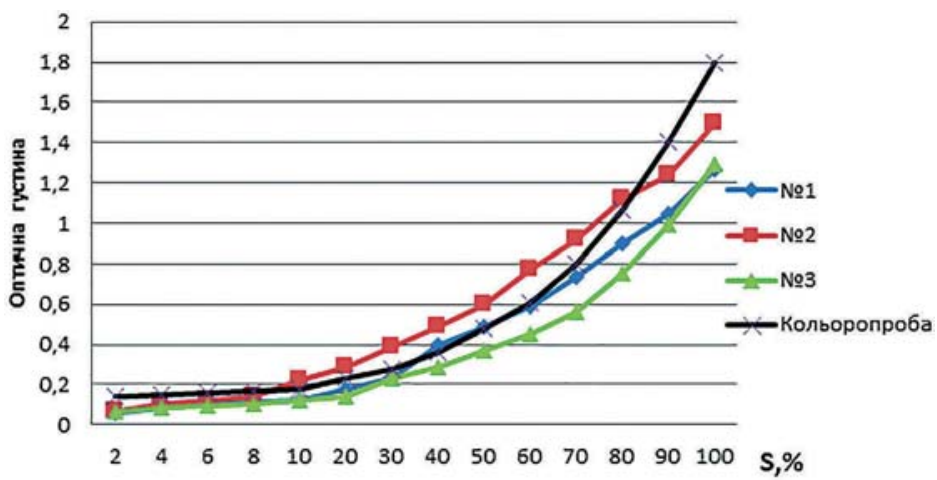

б

Рис. 2. Градаційна передача пурпурної фарби Magenta Huber Group cepiï: a - Resista, б - Reflecta при швидкостях друку № 1, № 2, № 3 
і зниження густини у взірців № 1 і № 3 для двох комплектів фарб. В півтонах (рис. 2, а) показники густини взірців № 1 і № 2 більшменш відповідають кольоропробі, зниження показника оптичної густини продовжується в темних ділянках. На рис. 3, б тоновідтворення взірця № 1 відповідає кольоропробі в півтонах і знижується в тінях, взірець № 2 демонструє зростання, а потім падіння площі растрових елементів. У взірця № 3 для двох комп- лектів фарб Resista та Reflecta спостерігається значне зниження густини, починаючи з півтонів і темних ділянок.

Стабільність градаційної передачі жовтої фарби (рис. 3) спостерігається в світлих ділянках і півтонах для всіх досліджуваних взірців, тоді як в темних ділянках їх густина знижується. Як видно з рис. 3, б, для взірця № 1, починаючи з поля 50 \%, відбувається зменшення площі елементів. В темних ділянках віднос-

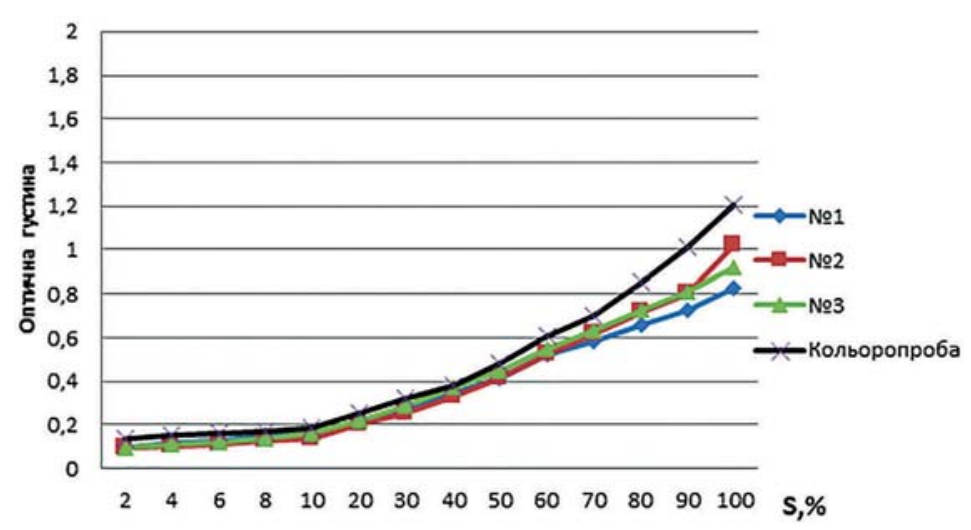

a

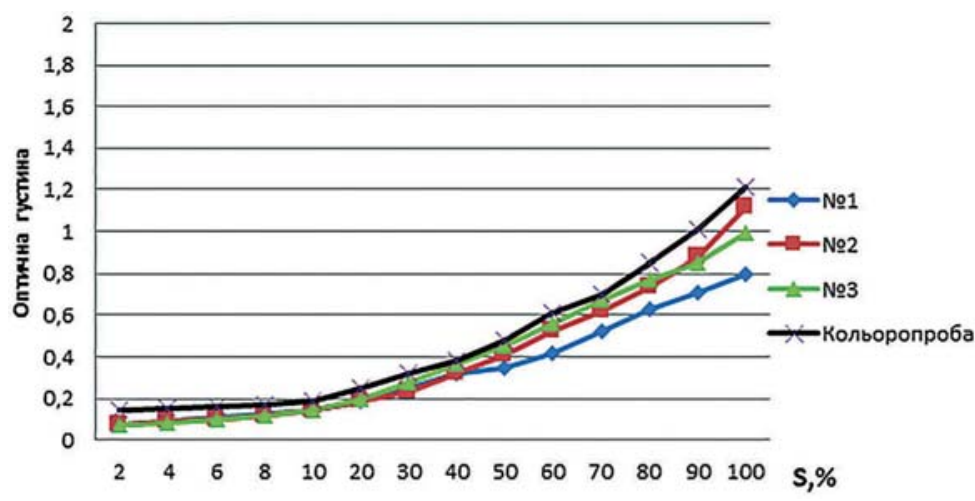

б

Рис. 3. Градаційна передача жовтої фарби Yellow Huber Group cepiï: a - Resista, б - Reflecta при швидкостях друку № 1, № 2, № 3 
на площа растрових елементів зменшується відносно еталонного взірця при всіх швидкостях друку для двох комплектів фарб Resista тa Reflecta.

3 графічних залежностей передачі чорної фарби досліджуваних взірців, представлених на рис. 4, помітно стабільну подачу фарби іплощу растрових елементів в світлих ділянках. Починаючи з півтонів оптична густина взірців № 1 і № 3 починає зростати і це продовжується і в темних ділянках, співпадаючи з кольоро- пробою на ділянці $100 \%$. У взірця № 2 збільшення оптичної густини $є$ незначною, хоча на ділянці 100 \% дещо не дотягує до еталонного взірця.

\section{Висновки}

В даній роботі розглянуто сучасні тенденції на ринку паковань, які передбачають підвищення вимог до якості їх поліграфічного оформлення. Офсетний друк визначений домінуючою світовою технологією виготовлення паковань завдяки можливості

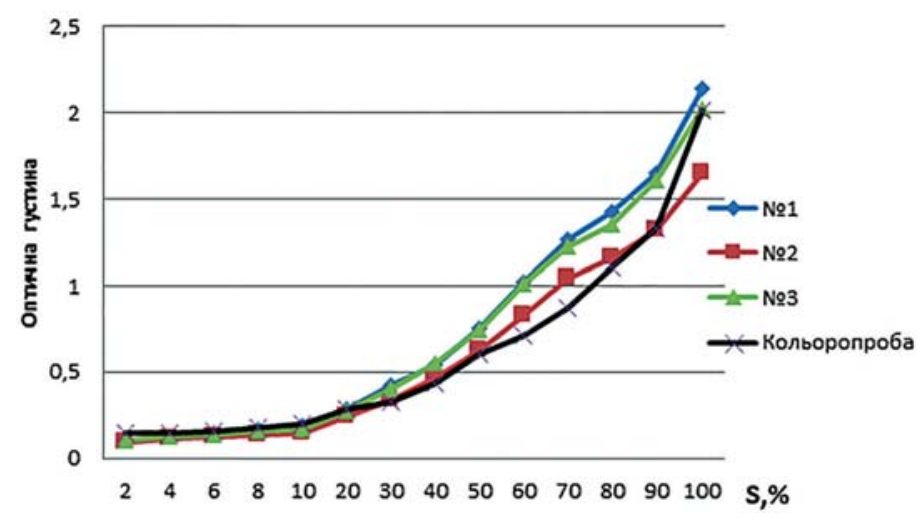

a



Рис. 4. Градаційна передача чорної фарби Black Huber Group cepiї:

a - Resista, б - Reflecta при швидкостях друку № 1, № 2, № 3 
забезпечення низької вартості та високої якості готової пакувальної продукції.

Проведено експериментальні дослідження впливу зміни технологічних режимів друкування на якість тоновідтворення зображення, в результаті яких вдалося встановити, що в світлих ділянках всі досліджувані взірці показали результат, наближений до кольоропроби. В півтонах найбільш нестабільна передача градацій, як видно з графічних залежностей для фарби Cyan i Magenta. В темних ділянках $€$ відхилення від кольоропроби у всіх взірцях, найстабільніше градацію передає взірець № 2, з незначними відхиленнями для пурпурної фарби, де стабільнішою виглядає тонопередача взірця № 1. В темних ділянках досліджуваних взірців $€$ відхилення від кольоропроби, найбільш наближено передається градація фарб у взірця № 2. Проаналізувавши отримані результати можна сказати, що найбільш стабільніше відтворилась передача фарб Yellow i Black для всіх досліджуваних взірців при друкуванні двома комплектами фарб з незначними відхиленнями від оптичної густини кольоропроби.

Підсумовуючи отримані результати, можна сказати, що в нашому експерименті для досягнення максимальної якості виготовлення картонного паковання, найкраще зарекомендував себе взірець № 2 при друкуванні двома комплектами фарб на однофарбовій офсетній машині Heidelberg GTO 52. Саме при швидкості друкування 5000 аркушів за годину спостерігається найбільш наближене до еталонного взірця відтворення зображення, тому саме таку швидкість друку можна рекомендувати використовувати при виготовленні паковань та ін. продукції.

\section{Список використаної літератури}

1. Importance of offset printing in commercial packaging industry [Електронний ресурс]. Режим доступу: http://medium.com/@elena.pakboxes/ importance-of-offset-printing-in-commercial-packaging-industry-4f1c97d1bceb.

2. Dunlap Sh. Digital vs. Offset Printing for Packaging: Which one to choose? / Dunlap Shanon [Електронний ресурс]. Режим доступу: http://pakfactory. com/blog/digital-vs-offset-printing-for-packaging-which-one-to-choose/.

3. Bernatsek V. Prospects of the offset printing of environmental packaging for food products / V. Bernatsek, M. Labetska // тези конференції тези X міжнародна науково-практична конференція «Квалілогія книги» (12 вересня 2019 року): матер. конФ. Львів: УАД, 2019. С. 51-54.

4. С. Ф. Гавенко. Дослідження впливу офсетних друкарських форм CtP на репродукційно-графічні показники відбитків / С. Ф. Гавенко, В.В.Бернацек, М. Т. Лабецька // Технологія і техніка друкарства. 2017. № 2(56). С. 24-33. DOI: https://doi.org/10.20535/2077-7264.2(56).2017.96555.

5. Слоцька Л. С. Основи поліграфії: Навч. посібн. / Л. С. Слоцька, В. З. Маїк, Ю. М. Румянцев. Львів: УАД, 2012. 244 с.

6. The future of offset printing [Електронний ресурс]. Режим доступу: http://www.offsetprintingtechnology.com/2019/the-future-of-offset-printing/. 
7. Heidelberg gto 52. [Електронний ресурс]. Режим доступу: https:// drukarstvo.com/ru/heidelberg-gto-52/.

8. Konica Minolta bizhub PRESS C6000. [Електронний ресурс]. Режим доступу: https://init-digital.ru/catalog/archive_color/bizhub_press_c6000/.

9. ISO 12647-2: 2004 / Amd 1: 2007. Управління процесами виробництва кольороподілених напівтонових зображень, пробних і накладних відбитків. Частина 2: Офсетний аркушевий друк.

10. Шкала для контроля копирования офсетных форм. [Електронний peсурс]. Режим доступу: http://poligraftorg.ru/test_scale.php.

\section{References}

1. Importance of offset printing in commercial packaging industry. Retrieved from http://medium.com/@elena.pakboxes/importance-of-offset-printing-incommercial-packaging-industry-4f1c97d1bceb [in English].

2. Dunlap, Sh. Digital vs. Offset Printing for Packaging: Which one to choose? Retrieved from http://pakfactory.com/blog/digital-vs-offset-printingfor-packaging-which-one-to-choose/ [in English].

3. Bernatsek, V. \& Labetska, M. (2019). Prospects of the offset printing of environmental packaging for food products. Journal of Kvalilohiia knyhy, 51-54 [in English].

4. Havenko, S. F. \& Bernatsek, V. V. \& Labetska, M. T. (2017). Doslidzhennia vplyvu ofsetnykh drukarskykh form CtP na reproduktsiino-hrafichni pokaznyky vidbytkiv [Research of Influence of Offset Printing Plates CtP on Graphic and Reproduction Parameters of Imprints]. Journal of Tekhnolohiia i tekhnika drukarstva, 2(56). C. 24-33. DOI: https://doi.org/10.20535/2077-7264.2(56). 2017.96555 [in Ukrainian].

5. Slotska, L. S. \& Maik, V. Z. \& Rumiantsev, Yu. M. (2012). Osnovy polihrafii [Basics of Printing]. Lviv: UAD, 244 p. [in Ukrainian].

6. The future of offset printing. Retrieved from http://www.offsetprintingtechnology.com/2019/the-future-of-offset-printing/ [in English].

7. Heidelberg gto 52. Retrieved from https://drukarstvo.com/ru/heidelberggto-52/ [in English].

8. Konica Minolta bizhub PRESS C6000. Retrieved from https://initdigital.ru/catalog/archive_color/bizhub_press_c6000/ [in English].

9. Upravlinnia protsesamy vyrobnytstva koloropodilenykh napivtonovykh zobrazhen, probnykh i nakladnykh vidbytkiv. Chastyna 2: Ofsetnyi arkushevyi druk [Management of Production Processes of Color-Separated Halftone Images, Trial and Overhead Prints. Part 2: Offset Sheet Printing]. ISO 12647-2: 2004 / Amd 1: 2007 [in Ukrainian].

10. Shkala dlya kontrolya kopirovaniya ofsetnykh form [Scale for Control of Copying of Offset Forms]. Retrieved from http://poligraftorg.ru/test scale.php [in Ukrainian].

\footnotetext{
Experimental researches of influence of change of printing technological modes (namely changes in printing speed), by different inks on quality of tone reproduction of imprints
} 
by establishment of their reproduction and graphic indicators are carried out in work. As a result of the analysis of the constructed graphic dependences of change of gradation transfer of inks of investigated samples and color proofing the optimum speed of packings printing by an offset method is established.

Keywords: offset printing; packaging; imprint; color proofing; tone reproduction; gradation transmission; optical density; quality.

\author{
Рецензент - О. В. Зоренко, канд. техн. наук, \\ доц., КПІ ім. Ігоря Сікорського
}

Надійшла до редакції 28.07.20 